\title{
The relationship in the cow between milk-fat secretion and ruminal volatile fatty acids
}

\author{
BY J. E. STORRY AND J. A. F. ROOK* \\ National Institute for Research in Dairying, Shinfield, Reading
}

(Received 3I May 1965-Accepted 3 December 1965)

\begin{abstract}
I. The effect of reducing the hay and of increasing the proportions of concentrate and flaked maize in the diet of cows on the secretion of milk fat and its component fatty acids and on the proportions of volatile fatty acids in the rumen liquor has been studied. 2. The low-hay diet caused a fall in the milk fat content to about half of the values in the initial control period and the secretion of all the major fatty acids in the milk was reduced. The general pattern of change in the proportions of rumen VFA during the change to the low-hay diet was a decrease in acetic acid, an increase in propionic and $n$-valeric acids, relatively little change in $n$-butyric acid and also an increase in the concentration of lactic acid. Approximately $60 \%$ of the variation in milk fat content during the change of diet was associated with the increase in propionic acid. 3. In cows established on the low-hay diet there were marked variations in the relative proportions of acetic and propionic acids, but there was no related change in milk fat content. On return of the animals to the high-hay diet, recovery of the initial proportions of acetic, propionic and valeric acids occurred within about 4 days but the recovery in milk fat content was not complete until 2-3 weeks had elapsed. 4. Although the intraruminal infusion of acetic acid in cows on the low-hay diet caused increases and decreases respectively in the molar proportions of acetic and propionic acids in the rumen, an increase in milk fat content was observed amounting to only one-quarter of the loss associated with the transfer to the low-hay diet; there was no characteristic pattern of increase in the yields of the individual fatty acids of milk fat. No consistent effects of intraruminal infusions of butyric acid, in cows on the low-hay diet, on the yield of milk fat or of the individual fatty acids were observed.
\end{abstract}

There is much circumstantial evidence that the fall in milk fat content frequently observed in milking cows during a change from a diet containing a usual amount of hay to one containing only a small amount is related to the associated decreased and increased proportions of acetic and propionic acids respectively in the volatile fatty acids of the rumen digesta. Marked variations from cow to cow in the extent and rapidity of the fall in fat content are, however, observed, and on the abrupt return of cows from a diet low in hay to one containing a usual amount, the recovery of the original fat content is not immediate but takes place progressively over a period of up to 3 weeks (Balch, Balch, Bartlett, Cox \& Rowland, r952; King \& Hemken, 1962; Storry \& Rook, I965a). Also when intraruminal additions of dilute acetic acid or of sodium acetate are given to cows receiving a diet low in hay and in whose milk the fat content has been depressed, the observed increases in milk fat content vary widely from cow to cow (Stoddard, Allen \& Peterson, I949; Tyznik \& Allen, r95 I; Balch \& Rowland, I959; Jorgensen, I964; Stanley, Morita \& Ueyama, I964). Such observations suggest that the relationship between milk fat content and the relative proportions in rumen digesta of acetic and propionic acids is not a simple one and that there may be other factors that contribute to the fall in milk fat content. A study has therefore been made with milking cows of the progressive changes in milk-fat secretion and

* Present address : Department of Agriculture, University of Leeds. 
ruminal volatile fatty acids that occur during a change from a diet containing a usual amount of hay to one containing only a small amount, and of those that follow an abrupt return from this low-hay diet to the original one. Also, in the intervening period when the cows received the low-hay diet continuously, the effects of intraruminal additions of acetic acid or of butyric acid on milk-fat secretion and ruminal volatile fatty acids were investigated.

\section{EXPERIMENTAL}

Animals and their management. Four lactating Friesian cows fitted with permanent rumen fistulas were used. Three of the cows (Bride I5 $_{5}$ Bride 20 and Eileen) were offered daily a control diet of $8 \mathrm{~kg}$ meadow hay and Io $\mathrm{kg}$ dairy concentrate cubes for a preliminary period of ${ }_{5} 5$ days and for a further experimental period of 3 days. The diet was then changed progressively over a period of ro days to I $\mathrm{kg}$ meadow hay, $7 \mathrm{~kg}$ concentrate cubes and $7 \mathrm{~kg}$ flaked maize, referred to subsequently as a 'low-hay diet'. After 7 days on the low-hay diet, continuous intraruminal infusions of acetic acid ( $1500 \mathrm{ml}$ in $15 \mathrm{gal}$ water/day) and of butyric acid ( $75^{\circ} \mathrm{ml}$ in 15 gal water/day) were each given separately and in varying order from cow to cow for periods of 14 days with an intervening period of 17 days and there was then a final period of 7 days on the low-hay diet; infusions of water only were given in the intervening period and for 6 days before and after the infusions. The acids were $96-97 \%$ pure and the main contaminants were other lower volatile fatty acids. An abrupt return was then made to the original diet, and after a further 2 I days the cows were removed from experiment.

The fourth cow, Bride 17, was offered daily a control diet of $8 \mathrm{~kg}$ meadow hay and $7 \mathrm{~kg}$ concentrate cubes for a preliminary period of $\mathrm{I}_{5}$ days and a further experimental period of 3 days. The diet was then changed progressively over a period of 12 days to I $\mathrm{kg}$ meadow hay and $7 \mathrm{~kg}$ flaked maize. After 6 days on this low-hay diet the cow was removed from experiment.

The daily diets were offered in two equal parts at 06.00 and $15.00 \mathrm{~h}$.

Sampling and methods of analysis. Milk yield was recorded and samples of milk were taken at each milking. Daily composite samples were prepared and analysed for fat content by the Gerber method (British Standards Institution, I955). Weighted, composite samples representing 2 days were also prepared and analysed for the fatty acid composition of the milk fat by gas chromatography (Storry $\&$ Rook, $1965 b$ ).

On certain days at intervals throughout experimental periods, samples of rumen liquor were taken, through the fistula, from the liquid phase in the ventral sac of the rumen at $10.00,12.30,15.00$ and $17.30 \mathrm{~h}$. The samples of rumen liquor were strained through muslin and the $\mathrm{pH}$ was measured immediately. The liquor was centrifuged for $40 \mathrm{~min}$ at $2500 \mathrm{~g}$ and analysed for total volatile fatty acids (Annison, I954), individual fatty acids by gas chromatography (Storry \& Millard, I965) and lactic acid (Elsden \& Gibson, 1954). 


\section{RESULTS}

\section{Effect of a low-hay diet on rumen fermentation and milk fat content}

Rumen $p H$ and the total volatile fatty acids and lactic acid of rumen liquor. Similar trends were observed for all three cows and the mean of values for Bride 15 , Bride 20 and Eileen are shown in Fig. I. During the change from the control to the low-hay diet, $\mathrm{pH}$ decreased slightly from initial average daily values of $5 \cdot 5-5 \cdot 8$ to values within the range from $5 \cdot 2$ to $5 \cdot 5$. At the same time, there was a considerable increase in lactic
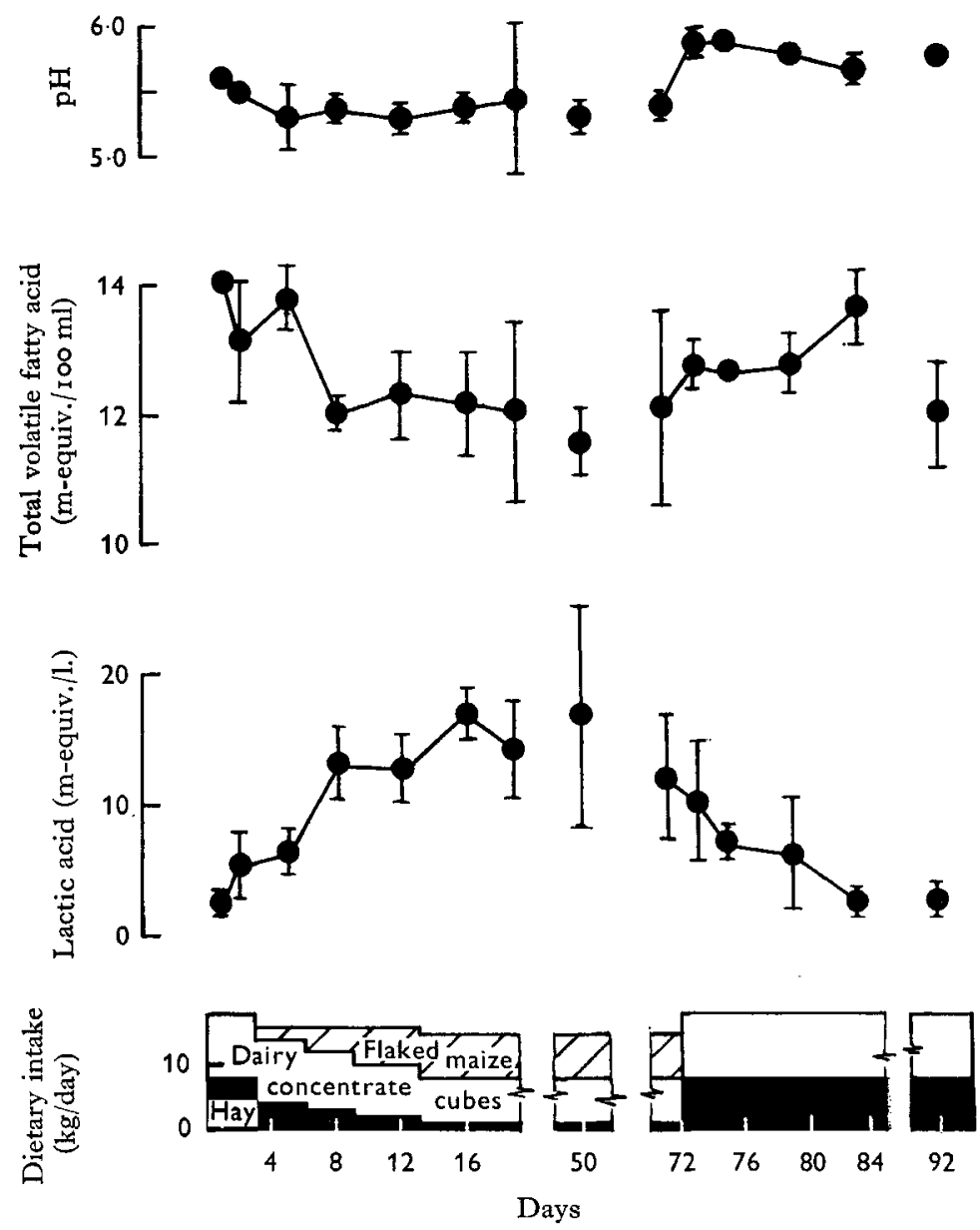

Fig. I. Variations with diet in $\mathrm{pH}$, total volatile fatty acids and lactic acid of rumen liquor of cows. Mean values with their standard errors for Bride 15 , Bride 20 and Eileen. Intraruminal infusions of acetic and butyric acid were given on days $19-33$ and days $5 I-64$.

acid concentration from initial mean daily values of about $5 \mathrm{~m}$-equiv. $/ 1$. to a maximum of $5^{-20} \mathrm{~m}$-equiv. $/ 1$. The usual marked variations in lactic acid concentration were observed throughout a day, the minimum value occurring invariably with the sample taken immediately before feeding and the maximum with the sample taken $2.5 \mathrm{~h}$ after 


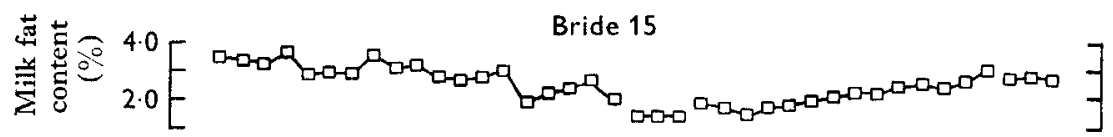

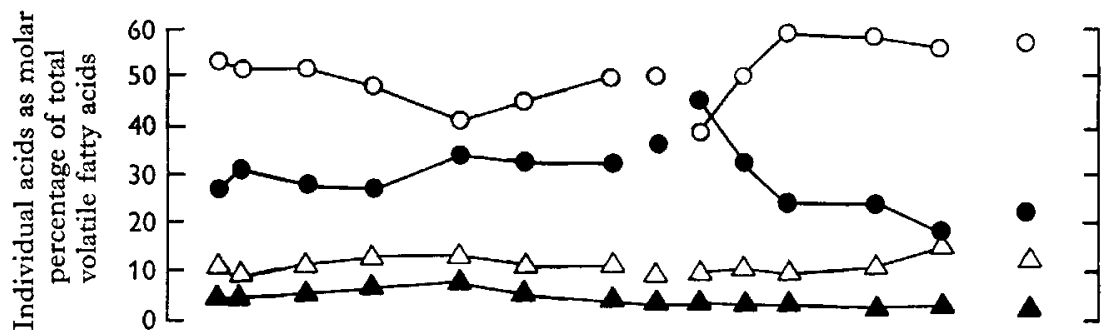

Bride 20

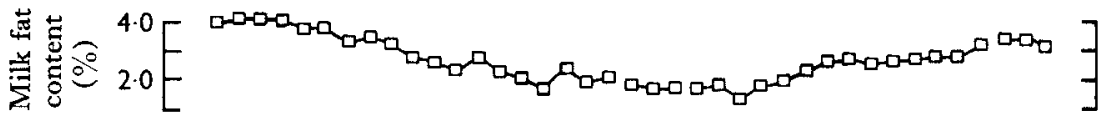

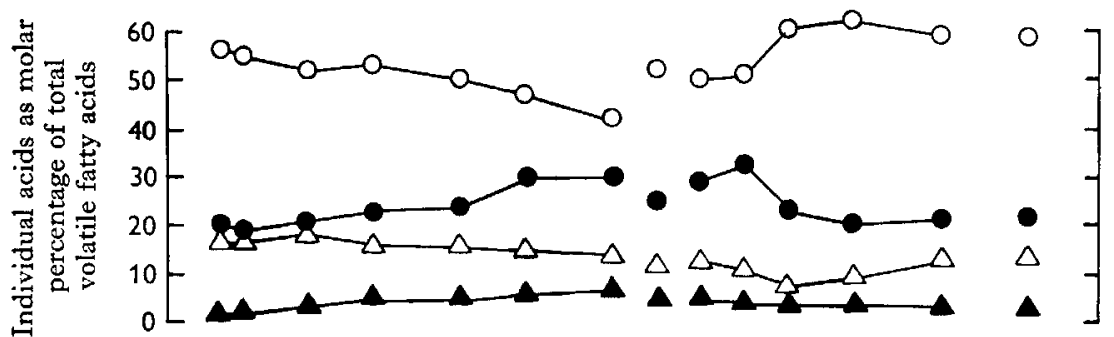

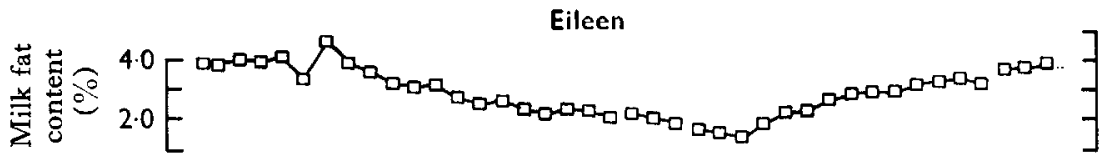
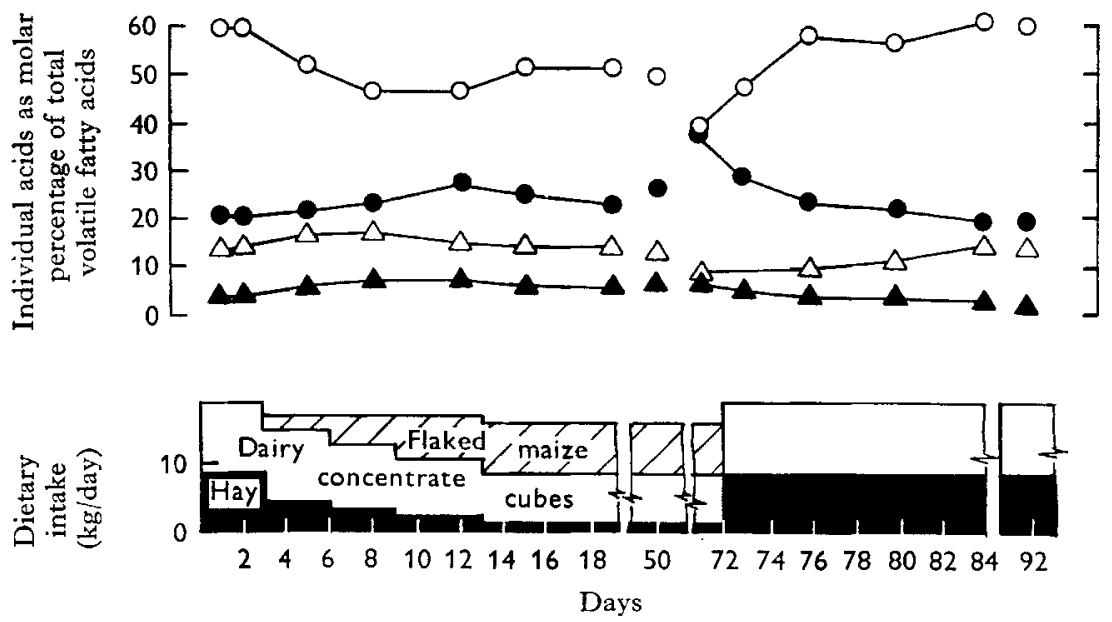

Fig. 2. Variations with diet for three cows, Bride 15 , Bride 20 and Eileen, in milk fat content and in the molar proportions of the individual volatile fatty acids of rumen liquor $(0-0$, acetic acid; $\bullet-\bullet$, propionic acid; $\Delta-\Delta, n$-butyric acid; $\Delta-\Delta, n$-valeric acid). Intraruminal infusions of acetate and butyrate were given on days $19-33$ and days $5 \mathrm{I}-64$. 
feeding. For the low-hay diets, maximum values were often of the order of $60-70 \mathrm{~m}$ equiv./1. With the abrupt return of the cows to the control diet there was an immediate increase in $\mathrm{pH}$, to values of $5 \cdot 8-6 \cdot 0$ which were slightly higher than those for the initial control period, and a progressive fall in lactic acid concentration to about the initial concentration after 1o days.
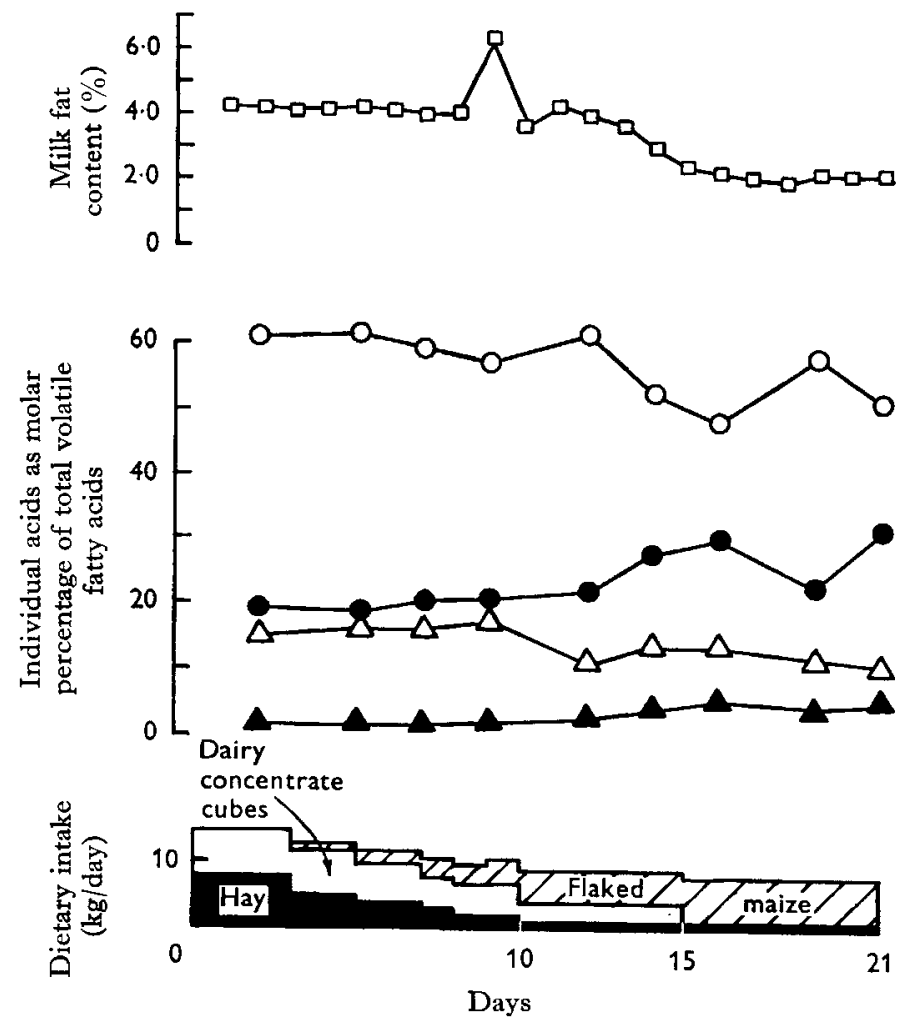

Fig. 3. Variations with diet, for a cow, Bride 17 , in milk fat content and in the molar proportion of the individual volatile fatty acids of rumen liquor $(0-0$, acetic acid; $\bullet \bullet$, propionic acid; $\Delta-\Delta, n$-butyric acid; $\Delta-\Delta, n$-valeric acid).

Wide variations in the mean daily concentrations of total volatile fatty acids occurred in all cows, but there was a general trend towards a decrease in concentration during the period when the low-hay diet was given and a recovery following the return to the control diet. Towards the end of the final control period, however, low values were again observed for all cows.

Ruminal volatile fatty acid proportions and milk fat percentage (Figs. 2 and 3 ). The overall changes in milk fat content and in the molar proportions of the individual fatty acids of rumen liquor were similar for all cows. With the change to the low-hay diet there was a general pattern of change in volatile fatty acid proportions, involving a decrease in acetic acid, increases in propionic and $n$-valeric acids and little change in $n$-butyric acid, in association with a decrease in milk fat content from about $3.5-4.0 \%$ to $2.0 \%$ or less. There were, however, important differences of detail from cow to cow. After 
an initial fall in the proportion of acetic acid there was a partial recovery with Eileen and a complete recovery with Bride $I_{5}$, and in both cows there was initially a small, temporary increase in butyric acid and a later more pronounced increase in propionic acid, which was associated with the most marked fall in fat content. In Bride 17 , the decrease in acetic acid and the increase in propionic acid were considerably delayed, until some 4 days after an extreme change of diet to $\mathrm{I} \mathrm{kg}$ hay, $3 \mathrm{~kg}$ concentrate cubes and $5 \mathrm{~kg}$ flaked maize daily, and there was a corresponding delay in the fall in milk fat content: initially butyric acid increased slightly, but it then decreased markedly before an increase in the proportion of propionic acid.

Using values for the milk fat content and for the molar proportions of acetic and propionic acids in rumen contents from each of the four cows on two occasions during the initial control period and on five occasions during the period of change to the lowhay diet, a multiple regression equation was estimated for each cow. There was no evidence of significant partial regression of fat percentage on the molar proportion of acetic acid, and multiple regressions were no more informative than simple regressions of fat percentage on the proportion of propionic acid (molar \% of total volatile fatty acids). These simple regressions shared a common slope $(b=-0.185)$ but were not coincident. On average, $63 \%$ of the variation in a cow's milk fat percentage was directly associated with variations in propionic acid.

For all cows, over the periods when the low-hay diet was given without an infusion of acid, there were marked variations from day to day and more particularly from period to period in the relative proportions of acetic and propionic acids, but there appeared to be no related change in milk fat content.

On the abrupt return of cows to the control diet there was a recovery to the initial proportions of acetic, propionic and valeric acids within about 4 days: for Bride 15 a higher proportion of acetic acid and a lower proportion of propionic acid were observed than during the initial control period. Variations in butyric acid showed no consistent pattern. In spite of the rapid recovery of the initial pattern of volatile fatty acids in the rumen, the recovery in milk fat content was slow. A value only slightly less than the initial for the control diet was eventually reached, in about 2 weeks in Bride 15 and Bride 20 and in about 3 weeks in Eileen.

\section{Effect of intraruminal infusions of acetic acid or of butyric acid on ruminal volatile fatty acids and on milk fat content}

The infusion of acetic acid caused an increase in rumen liquor in the molar proportion of acetic acid and a decrease in that of propionic acid; the effect on acetic acid was significant $(P<0.05)$ for Bride ${ }_{1} 5$ and Eileen and on propionic acid for Bride 15 . The effects on butyric acid were small and variable. The infusion of butyric acid had no measurable effect on the molar proportions of the individual fatty acids of rumen liquor in Bride $\mathrm{I}_{5}$, but with Bride 20 and Eileen there was a significant $(P<0.05)$ increase in the proportion of butyric acid and in addition an increase in that of acetic acid and a decrease in that of propionic acid (Table I). The change in the relative proportions of acetic and propionic acids was progressive throughout the period of 
infusion of butyric acid and in Bride 20 the altered pattern remained after the infusion of butyric acid had been stopped (Fig. 4).

Infusion of acetic acid caused small increases in milk fat content, but only for Bride 15 was the effect significant $(P<0.05)$ (Table 2). The response was of the order of only one-quarter of the loss in fat content associated with the transfer of the cows from the control to the low-hay diet, and there was no evidence of a greater increase in fat content towards the end of the 14 -day infusion period than at the beginning. Associated increases in the yields of individual fatty acids in milk were

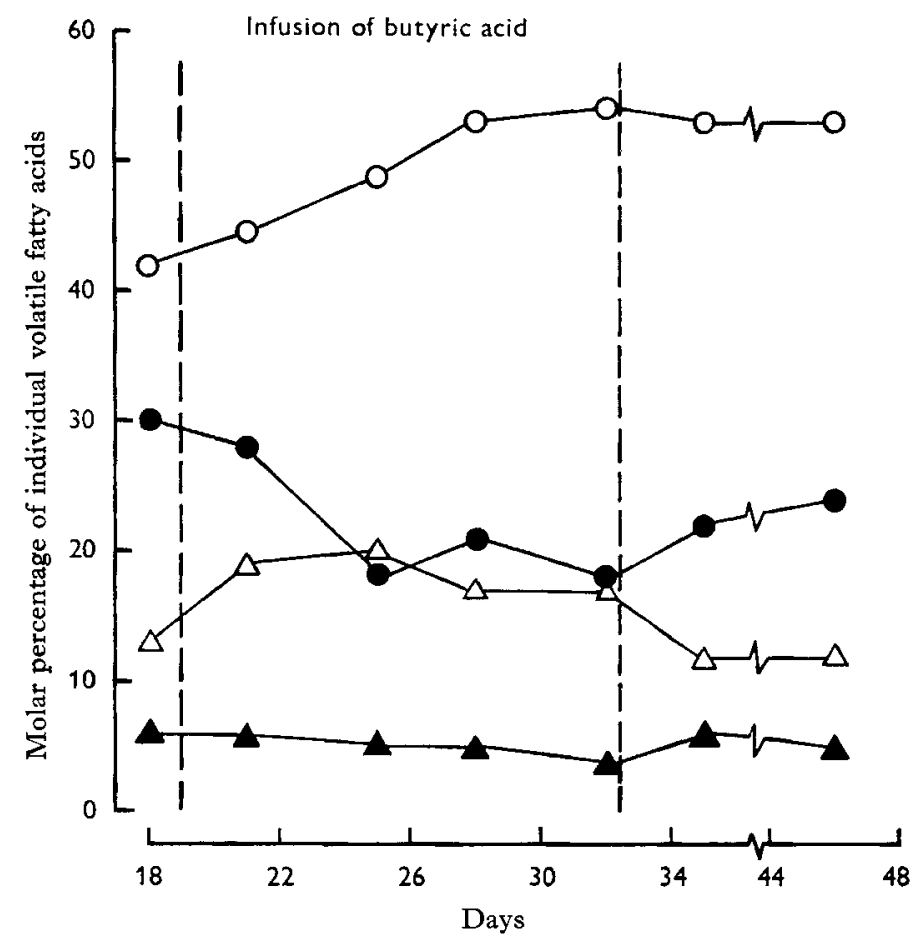

Fig. 4. Effect in a cow, Bride 20 , of an intraruminal infusion of $750 \mathrm{ml}$ butyric acid on the molar proportions of the individual volatile fatty acids in rumen liquor $(0-0$, acetic; $-\bullet$, propionic; $\Delta-\Delta, n$-butyric; $\Delta-\Delta, n$-valeric). The infusion of butyric acid was given on days I $9-33$.

correspondingly low and no characteristic pattern of response emerged. For Eileen there was a peak in milk fat percentage and in fat yield after about 5 days of the infusion but by the end of the infusion period the values had returned to the preinfusion levels.

The effect of the infusion of butyric acid on milk fat percentage and yield and on the yields of individual fatty acids was small, and variable from cow to cow (Table 3 ). 
Table I. Effects of intraruminal infusions of acetic acid and of butyric acid in three cows receiving a diet low in hay and high in flaked maize on $\mathrm{pH}$, the concentration of total volatile fatty acids and the molar proportions of individual volatile fatty acids in rumen liquor. Rumen liquor was sampled on 2 days in the 6-day period preceding the infusion of acid and on 4 days at intervals throughout the $\mathrm{I}_{4}$-day infusion period

\begin{tabular}{|c|c|c|c|c|c|}
\hline \multicolumn{2}{|c|}{ Bride 15} & \multicolumn{2}{|c|}{ Bride 20} & \multicolumn{2}{|c|}{ Eileen } \\
\hline $\begin{array}{l}\text { Mean value } \\
\text { during } \\
\text { infusion of } \\
\text { water only }\end{array}$ & $\begin{array}{c}\text { Change with } \\
\text { infusion } \\
\text { of acid } \dagger\end{array}$ & $\begin{array}{l}\text { Mean value } \\
\text { during } \\
\text { infusion of } \\
\text { water only }\end{array}$ & $\begin{array}{l}\text { Change with } \\
\text { infusion } \\
\text { of acid } \dagger\end{array}$ & $\begin{array}{c}\text { Mean value } \\
\text { during } \\
\text { infusion of } \\
\text { water only }\end{array}$ & $\begin{array}{l}\text { Change with } \\
\text { infusion } \\
\text { of acid } \dagger\end{array}$ \\
\hline
\end{tabular}

$\mathrm{pH}$

Total volatile fatty acids (m-equiv./100 ml)

Acetic acid infusion

Individual acids, as molar percentages of total volatile fatty acids:

Acetic

Propionic

n-Butyric

$$
\begin{array}{cr}
5.2 & -0.1 \pm 0.08 \\
13.16 & +0.07 \pm 0.28
\end{array}
$$

$$
5.2-0.2 \pm 0.14
$$

II.29+2.81 $\pm 0.39^{*}$ $\begin{array}{cl}5.5 & -0.3 \pm 0.16 \\ \text { II.96 } & +I .48 \pm 0.95\end{array}$

\section{$\mathrm{pH}$}

Total volatile fatty acids

(m-equiv./100 ml)
$+14.3 \pm 2 \cdot 85^{*}$

$-11 \cdot 9 \pm 2 \cdot 16^{*}$

$-0.3 \pm 0.29$

$52 \cdot 7$

24.4

I I. 8

$+6 \cdot 1 \pm 3 \cdot 34$

$-5 \cdot 3 \pm 2 \cdot 17$

$+0.4 \pm 0.43$

Butyric acid infusion

$-0.3 \pm 0.12$

$+0.1 \pm 0.20$

II. $19+0.39 \pm 0 \cdot 36$

Individual acids, as molar per-

\begin{tabular}{|c|c|c|c|c|c|c|}
\hline Acetic & $48 \cdot 2$ & $-3 \cdot 0 \pm 1 \cdot 78$ & $4 I \cdot 9$ & $+8 \cdot 3 \pm 2 \cdot 1 I^{*}$ & $49^{\circ} \mathrm{I}$ & $+2 \cdot 8 \pm I \cdot I 8$ \\
\hline Propionic & $3^{6 \cdot I}$ & $+0.8 \pm 2.77$ & $29 \cdot 7$ & $-8 \cdot 8 \pm 2.06 *$ & $26 \cdot 1$ & $-7 \cdot 3 \pm 1.09 *$ \\
\hline$n$-Butyric & $8 \cdot 6$ & $+0.7 \pm I \cdot 39$ & 13.4 & $+4.5 \pm 0.76$ & 12.5 & $+5.5 \pm 0.30^{*}$ \\
\hline
\end{tabular}

centages of total volatile fatty acids:

$* P<0.05$, where $P$ is the probability that a difference as large as the observed difference could have arisen by chance.

$\dagger$ Mean values with their standard errors.

\section{DISCUSSION}

Our results are consistent with earlier evidence of a characteristic pattern of change in ruminal volatile fatty acids, of a decrease in the proportion of acetic acid, an increase in the proportions of propionic and $\boldsymbol{n}$-valeric acids and little change in the proportion of $n$-butyric acid, in association with the fall in milk fat content in milking cows during a transfer from a high-hay to a low-hay diet. Of the variation in fat percentage in the initial control period and throughout the period of change from the control to the low-hay diet, some $60 \%$ was directly related to variations in the molar proportion of propionic acid in the total volatile fatty acids of rumen liquor. This represents a high proportion of the total variation, in view of the known marked variation from milking to milking in the completeness of removal of milk fat from the udder. The less close relationship over the same period between milk fat content and the proportion of acetic acid in the total volatile fatty acids of rumen liquor probably arose because acetic acid varied also in association with butyric acid. Such variation would oppose a direct relationship between fat content and the proportion of acetic acid in rumen 


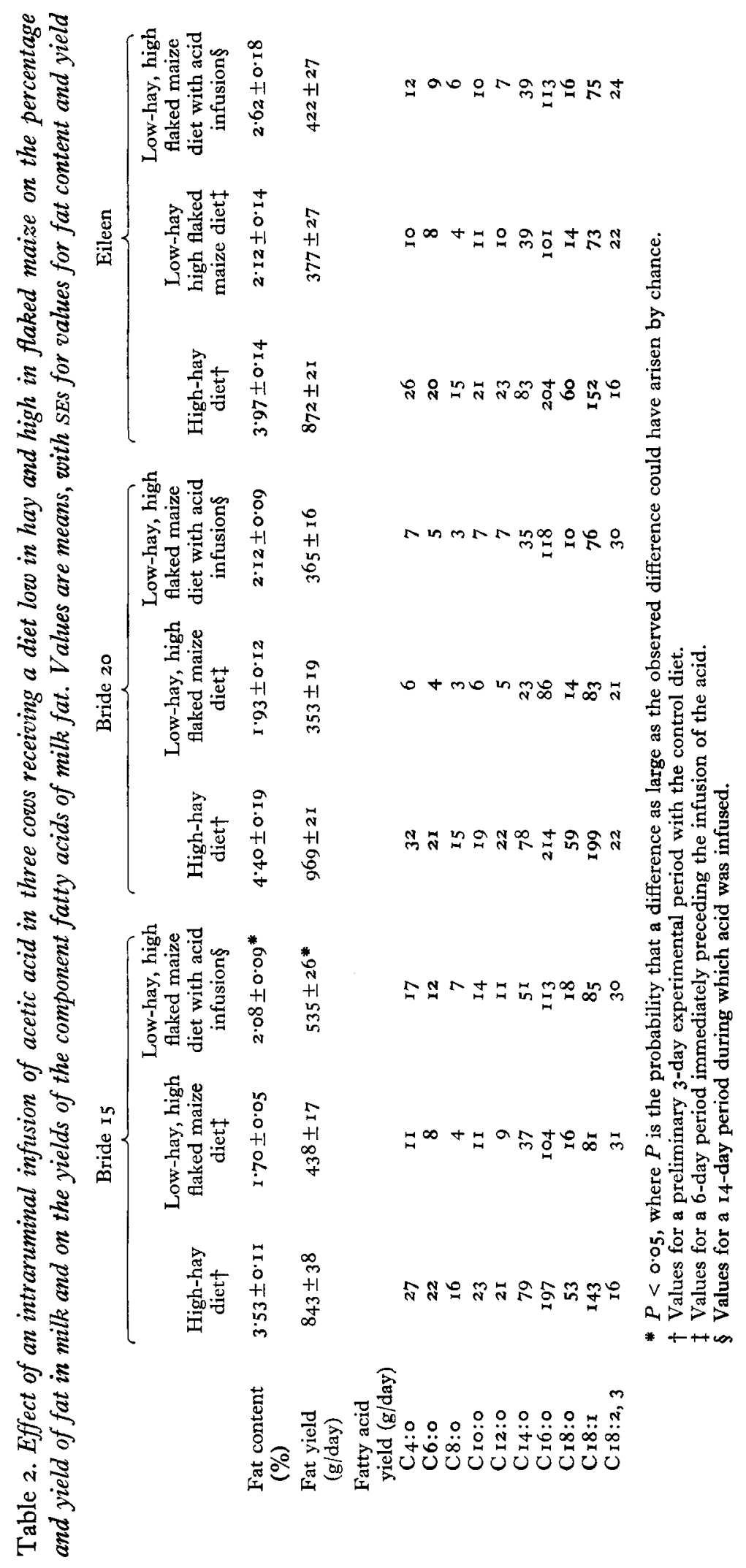




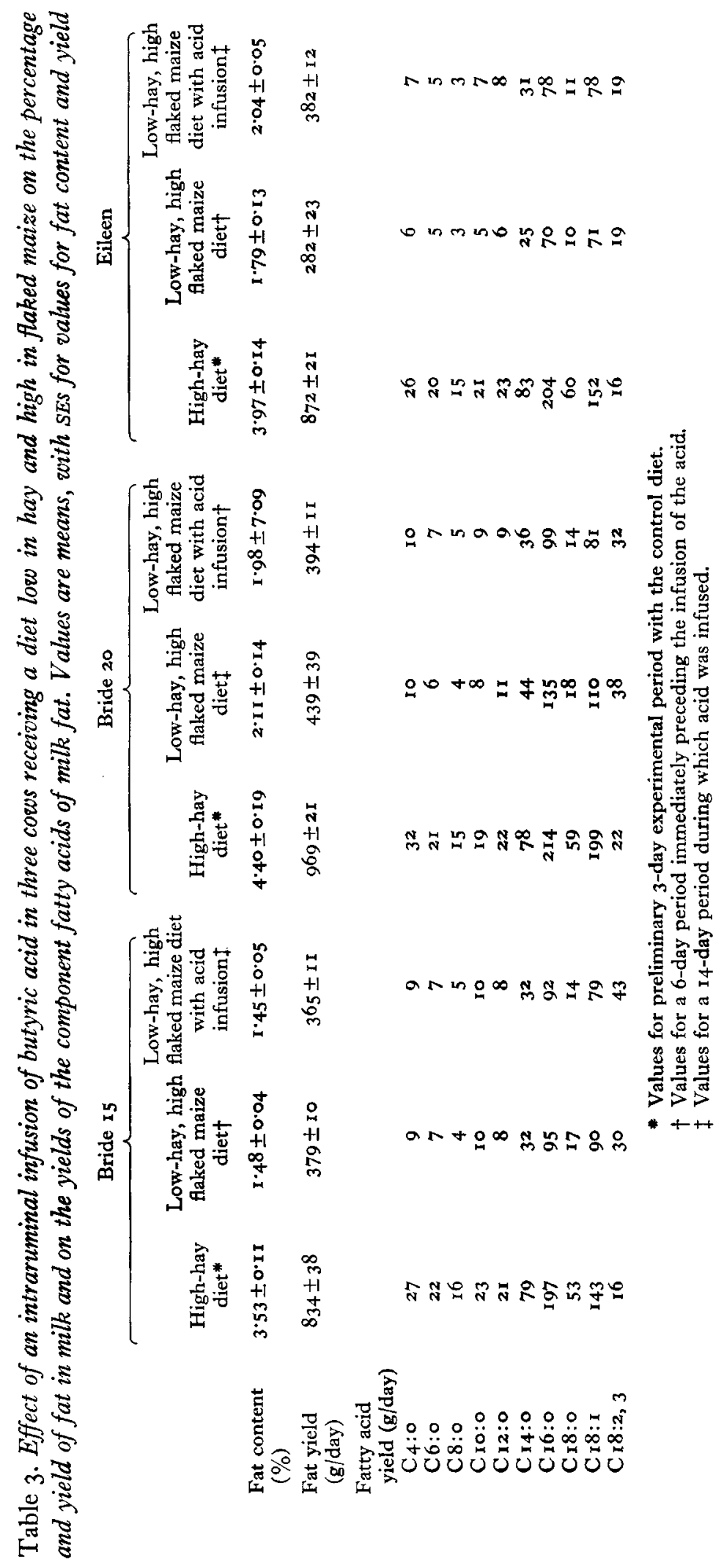


liquor, since with diets containing a usual amount of hay, infusion of butyric acid is as effective as infusion of acetic acid in promoting a high milk fat content (Rook \& Balch, I96r). There is much additional evidence (Donefer, Lloyd \& Crampton, I962; Blaxter \& Wainman, I964; Bath \& Rook, I965) that the replacement of hay in a diet with concentrates can cause a fall in the proportion of acetic acid in ruminal volatile fatty acids which is compensated by an increase not in propionic acid, but in butyric acid, and more particularly when the proportion of concentrates in the diet is low and when the concentrates are based largely on barley as opposed to flaked maize. Such a change in the pattern of fermentation could explain why the milk fat content did not fall when certain cows were given a diet low in hay (cf. Balch, Broster, Rook \& Tuck, 1965) and the considerable delay in the fall in fat content in the milk of other cows as, for example, in Bride $\mathbf{I} 7$ in the experiments described here.

A much less consistent relationship between the pattern of volatile fatty acids within the rumen and milk fat content was found, however, once the cows were established on a low-hay diet and following an abrupt return to the control diet. Over the period when a low-hay diet was offered and excluding the periods when infusions of acids into the rumen were made, there was a considerable variation in the relative proportion of acetic to propionic acid without any related change in milk fat content. After the abrupt return of cows from the low-hay to the high-hay diet there was a rapid recovery of the original proportions of acids in the rumen liquor whereas the recovery in fat content was slow.

Also, when the cows were receiving low-hay diets the responses in milk fat content to intraruminal infusions of acetic or butyric acids did not conform with observations made with cows given diets containing usual amounts of hay (Rook \& Balch, I96I). In none of the three cows was there a response in fat content to an infusion of butyric acid, in spite of a marked increase in two of the cows in the proportion of butyric acid in the volatile fatty acids of rumen liquor. Two out of three cows showed a response in fat content to an infusion of acetic acid, but the effect was slight, whereas the molar proportions of acetic acid in rumen liquor increased to a value similar to that observed with the control diets. If, as seems probable, the initial depression in milk fat content is the combined result of a decreased synthesis of short-chain $\left(\mathrm{C}_{4}-\mathrm{C}_{1} 6\right)$ fatty acids because of a reduced ruminal production of acetate and of a decreased secretion of $\mathrm{C}_{1} 8$ acids because of an increased production of propionic acid (see Rook \& Storry, 1964), a complete recovery in fat content in response to intraruminal additions of acetic acid would not be expected. In the experiments presented here, however, even recovery of the yields of the $\mathrm{C}_{4}-\mathrm{C}_{1} 6$ acids was far from complete. Widely variable recoveries in fat content of the milk of cows receiving low-hay diets and in which milk fat content had been depressed, after intraruminal additions of acetic or butyric acids or of sodium acetate or dietary additions of sodium acetate, have been reported in the literature (Stoddard et al. 1949; Tyznik \& Allen, I95 I; Balch \& Rowland, I959; Jorgensen, 1964; Jorgensen, Schultz \& Barr, I965). An explanation for these discrepancies cannot be given. It is clear, however, that with cows receiving low-hay diets there may be factors that limit the expected response in milk-fat secretion to increases in ruminal acetate and butyrate; these are now being investigated. 
Observations made during the infusion of butyric acid highlight one important point: the pattern of fermentation within the rumen, as reflected in the relative proportions of volatile fatty acids in rumen liquor, is more variable and unstable with low-hay diets than with diets containing the usual amount of hay. In two out of three cows, the infusion of butyric acid caused a considerable increase in the proportion of acetic acid and a decrease in that of propionic acid in addition to the expected increase in the proportion of butyric acid, and in one cow the original pattern was not recovered when the infusion was stopped. It is known that there is interconversion between all volatile fatty acids in the rumen (Gray, Pilgrim, Rodda \& Weller, 1952; Sheppard, Forbes \& Johnson, I959; Gray, Jones \& Pilgrim, I960) and that between acetate and butyrate appears to be quantitatively the most significant (Bergman, Reid, Murray, Brockway \& Whitelaw, I965). However, no comparable change in the pattern of fermentation has been observed when intraruminal additions of acids have been made to diets containing more usual proportions of hay to concentrates (Rook, Balch, Campling \& Fisher, 1963).

We thank Mr A. J. Hall, Mr D. Millard and Mr A. F. Hamnet for skilled technical assistance, $\mathrm{Mr} \mathrm{V}$. W. Johnson for care of the experimental animals and Mr D. R. Westgarth for statistical analysis of the results.

\section{REFERENCES}

Annison, E. F. (r954). Biochem. $\%$. 58, 670.

Balch, C. C., Balch, D. A., Bartlett, S., Cox, C. P. \& Rowland, S. J. (r952). F. Dairy Res. 19, 39.

Balch, C. C., Broster, W. H., Rook, J. A. F. \& Tuck, V. J. (1965). F. Dairy Res. 32, I.

Balch, C. C. \& Rowland, S. J. (1959). F. Dairy Res. 26, 162.

Bath, I. H. \& Rook, J. A. F. (1965). F. agric. Sci., Camb., 64, 67.

Bergman, E. N., Reid, R. S., Murray, M. G., Brockway, J. M. \& Whitelaw, F. G. (1965). Biochem. $\mathcal{F}$. 97, 53 .

Blaxter, K. L. \& Wainman, F. W. (1964). F. agric. Sci., Camb., 63, 113.

British Standards Institution (x955). B.S. 696, Part 1, p. 7.

Donefer, E., Lloyd, L. E. \& Crampton, E. W. (I962). F. Anim. Sci. 21, 993.

Elsden, S. R. \& Gibson, Q. H. (1954). Biochem. F. 58, I 54.

Gray, F. V., Jones, G. B. \& Pilgrim, A. F. (1960). Aust. $\mathscr{~ F . ~ a g r i c . ~ R e s . ~ 1 1 , ~} 383$.

Gray, F. V., Pilgrim, A. F., Rodda, H. J. \& Weller, R. A. (I952). F. exp. Biol. 29, 57.

Jorgensen, N. A. (1964). Diss. Abstr. 25, 2128.

Jorgensen, N. A., Schultz, L. H. \& Barr, G. R. (1965). F. Dairy Sci. 48, 1031.

King, R. L. \& Hemken, R. W. (1962). F. Dairy Sci. 45, г336.

Rook, J. A. F. \& Balch, C. C. (I96r). Br. F. Nutr. 15, 36r.

Rook, J. A. F., Balch, C. C., Campling, R. C. \& Fisher, L. J. (1963). Br. Y. Nutr. I7, 399.

Rook, J. A. F. \& Storry, J. E. (1964). Chemy Ind. p. 1778.

Sheppard, A. J., Forbes, R. M. \& Johnson, B. C. (1959). Abstr. Pap. Am. chem. Soc. 135th Mtg, p. II A.

Stanley, R. W., Morita, K. \& Ueyama, E. (I964). F. Dairy Sci. 47, 258.

Stoddard, G. E., Allen, N. N. \& Peterson, W. H. (1949). F. Anim. Sci. 8, 63 o.

Storry, J. E. \& Millard, D. (1965). F. Sci. Fd Agric. 16, 4 I7.

Storry, J. E. \& Rook, J. A. F. (1965a). Br. F. Nutr, 19, Iо1.

Storry, J. E. \& Rook, J. A. F. $\left(1_{965}\right.$ b). Biochem. J. $95,473$.

'Tyznik, W. \& Allen, N. N. (I95 I). F. Dairy Sci. 34, 493. 